\title{
Hydroxyapatite as a nanomaterial for tissue engineering and drug therapy
}

\author{
Juha Tuukkanen ${ }^{* 1}$, Miho Nakamura ${ }^{1,2}$ \\ ${ }^{1}$ Department of Anatomy and Cell Biology, Institute of Cancer and Translational Medicine, \\ University of Oulu, Oulu, Finland; ${ }^{2}$ Institute of Biomaterials and Bioengineering, Tokyo Medical \\ and Dental University, Tokyo, Japan
}

\begin{abstract}
Hydroxyapatite (HAp) is a complicated ceramic material, that varies between the way it appears in biological systems and how it is synthesized as various calcium phosphates. HAp varies in chemical composition of substituting atoms, crystallinity, grain size and electrical polarization. HAp can form solid to macro-, micro- and nanoporous structures. Also particulate HAp can have highly porous structure. HAp can be used as coatings for metal implants in thicknesses from hundreds of microns down to hundreds of nanometers. Cotton wool-like HAp fibers can be electrospun compounded with polymers (or without) for tissue engineering (TE) scaffolds. This review describes the features of HAp that may be utilized further in developing novel applications. As a nanomaterial HAp has been applied for drug delivery. The absorption of proteins and other compounds can be adjusted by modifying HAp composition, electrical polarization and wettability. Of special interest are the bisphosphonates that bind to HAp and thereby can be used to treat bone loss and also couple other drugs to the mineral. A new area for HAp constructs may appear in treating metallosis. HAp coating may function as a scavenger for the ions release from metal implants and thereby inhibit the adverse effects of the ion burden for the body. So far HAp is considered as safe biomaterial but nanoHAp may insidiously possess adverse effects especially when ingested by cells and eliciting excess intracellular calcium. Thereby critical approach also for HAp biomaterials is of utmost importance.
\end{abstract}

Keywords: Calcium phosphate, mineral, osteoblast, osteoclast, mesenchymal stem cell, bisphosphonate, scaffold, bone.

\section{INTRODUCTION}

Hydroxyapatite (HAp) is one of the safest biomaterial in tissue engineering and for that reason also widely used. Pure HAp has low dissolution and it is poorly resorbed by osteoclasts but its resorbability can be increased with chemical modifications [1-3]. It has been used in hundreds of types of constructs including coatings, discs, granules, porous materials and as an additive material in cements and polymeric implants. Nano HAp is used as granules and fibers. There are very little of adverse effects reported of HAp but more research is needed to better understand the usefulness and applications for HAp. All materials used in the human body should be taken carefully and keeping in mind that adverse effects may appear suddenly and there where no one could anticipate them to appear. Thus all biomaterials should be studied intensively and also HAp should be continuously investigated for dangers on health but also for new applications and application techniques.

A new concern has been raised on another widely used implant material, titanium. Titanium has been considered as well tolerated, biocompatible and a material that resists the

*Address correspondence to this author at the Department of Anatomy and Cell Biology, Institute of Cancer and Translational Medicine, University of Oulu, Oulu, Finland, P.O. Box: 90014, Oulu, Finland; Tel: $+358+40-$ 5858359; E-mails: juha.tuukkanen@,oulu.fi body burden of cellular processes and acidic environments. However, there is increasing evidence that titanium may release ions due to reasons like wear debris and fretting corrosion that generate reactive oxygen species around the implant $[4,5]$. Human body cannot deal with huge ion loads and can create an allergic or immunologic responses for the implant. This may stand also for other biomaterials. Whether HAp as a nanomaterial could be an active treatment in those cases is an open but interesting question. In this review we want to collect current data about nanoHAp and against that background to evaluate also its usefulness as scavenger of metallic ions and other substances and also as a drug carrier in tissue engineering. HAp has certain chemical properties that enable absorption and chemical bonding of drugs like bisphosphonates (BPs) that can have targeted pharmacological action or ability to function as a linker to particular proteins.

Tissue engineering especially and medicine as a whole cannot progress without biomaterials. When it now seems that biomaterials field may change fast and materials previously considered safe do have adverse effects, HAp should be reconsidered, because it is a natural constituent of our body. 


\subsection{Crystalline hydroxyapatite}

The stoichiometric HAp has $\mathrm{Ca} / \mathrm{P}$ molar ratio of 1.67 which is the most stable calcium phosphate at $\mathrm{pH} 4$ to 12 [6]. The biological HAp and synthetic HAp greatly differ in ion composition (and crystallinity). In bone matrix the mineral is composed of non-stoichiometric forms and substituted with trace elements, the most important being $\mathrm{Mg}, \mathrm{Si}, \mathrm{F}$ and especially carbonate $\mathrm{CO}_{3}{ }^{2-}[7]$.

Bone matrix is piezoelectric in nature [8]. Mechanical loading of bone generates an electrical potential by piezoelectricity arising from influences on both the collagen fibrils and the HAp mineral. Interestingly, an external voltage can polarize bone and synthesized HAp sample. The crystallographic c-axis orientation of calcined bone depends on the direction in which the bone is cut, either transverse or longitudinal, and the direction strongly affects the polarization efficacy [8].

The a (b)-planes of apatite crystal prefer positive charges and $\mathrm{c}$ planes are more negatively charged. Thus $\mathrm{a}$ and $\mathrm{b}$ bind negatively charged acidic proteins and $\mathrm{c}$ binds positively charged proteins [9]. In this respect the protein binding of HAp can be tailored by influencing the crystal orientation and charging of the material [10-14]. Electrical polarization has been shown to affect the osteogenic potential of HAp scaffolds. Polarization accelerates the adhesion and proliferation of osteoblasts and ossification already 3 weeks after surgery $[15,16]$. Big surface charges of electrically polarized HA ceramics enhance bone formation in vivo, regardless of the charge polarities, although the bone formation processes varies according to charge polarity. The electrostatically conditioned zones activate osteoprogenitor cells in the vicinities of the electrets [17]. Polarization may also affect other cellular functions like endothelial cells and angiogenesis in wound-healing [18].

The cell attachment on HAp depends on the natural coat on the surface of HAp. Various factors influence the protein adsorption and conformational changes in the coating molecules. The way of sintering the HAp scaffolds and coatings can greatly affect the surface characteristics of the material. The polarization of HAp crystal structure can be influenced by sintering in air or in saturated water vapor. Vapor increases the polarization capacity and surface free energy by increasing hydroxide ion content and grain size and thereby wettability of the surface. Higher wettability is beneficial for cell adhesion $[19,20]$.

\subsection{Hydroxyapatite as nanomaterial}

HAp materials can be used as particles (NPs), coatings, scaffolds and cements [21].The nano sized HAp bioceramics is an interesting area for biomedical applications. Due to the increased surface area and thus the better bioactivity of nanoHAp also the resorbability can be adjusted [22] [23].

However, the influence of nanomaterials at systems level are not fully understood and toxic reactions are serious concern
[24,25]. HAp particles smaller than 50nm were used to expose cells in vitro and skin of guinea pig in order to test the delayed hypersensitivity. The only detected adverse effects were those with human macrophages in vitro. It was concluded that the very high HAp ingestion caused too heavy calcium load for the cell after a time when the particulate materials started to dissolve intracellularly [25].

NanoHAp has also been suggested for drug delivery applications [9]. The particle size and shape may have big influence on cellular reactions and loading properties in drug delivery. Recently, the nanofibrous HAp fabrics have been developed [26,27] and tested for biocompatibility [28,29]. Interestingly, this kind of fibrous mat can perform as substrate for bone resorbing osteoclasts. The surface of this electrospun nonwoven scaffold is huge and it is biocompatible in vitro. However, the easily crumbling HAp fiber does not cause macrophage activation by its nanoscale morsels [29]. No in vivo tests have been studied so far. The mechanical properties of HAp are inferior to bone and it cannot be used in loadbearing implantation sites. Therefore, HAp may be used as thin layer on metal materials to increase the biocompatibility and osteoconductivity [30]. Another nanoHAp modification is so a called atomic layer deposition (ALD) nano coating of titanium implants (Fig. 2). 100 to 200 $\mathrm{nm}$ ALD coating is deposited in gas phase to form conformal and uniform HAp coating which sticks well on metal [31,32].

Pure HAp is very stable in body fluids. However, it can be slowly dissolved at grain boundaries. Nanostructured HAp has high surface area and thereby higher dissolution rate [33$35]$. Low crystallinity [36,37], carbonate incorporation [3] and contents of other ions [38] as well as small sized crystals influence the solubility and osteoclastic resorption (Fig. 1).

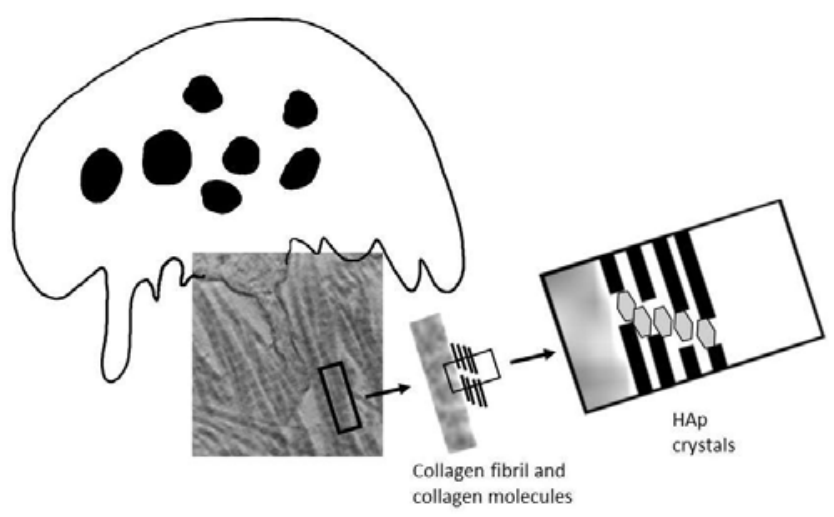

Figure 1. Osteoclast ruffled border penetrating to bone matrix between mineralized collagen fibers. The typical hexagonal HAp plate-like crystals fit structurally between the collagen fibrils in bone.

Bone mineral is not dissolved passively but due to active resorption by osteoclasts. When designing mineral scaffolds and coatings this should be considered [3]. 
When comparing bone healing around nanocrystalline hydroxyapatite, deproteinized bovine bone mineral, biphasic calcium phosphate, or autologous bone [39] it was found that in practice autologous bone is superior but nanocrystalline HAp performs well too. Powders, granules, porous and mesoporous nonleaded scaffolds, coatings on metal implants at load bearing sites and ceramic composite for polymeric scaffolds are the applications of HAp. However, the bigger HAp constructs suffer for brittleness but nano-sized structures and coatings may have interesting opportunities.

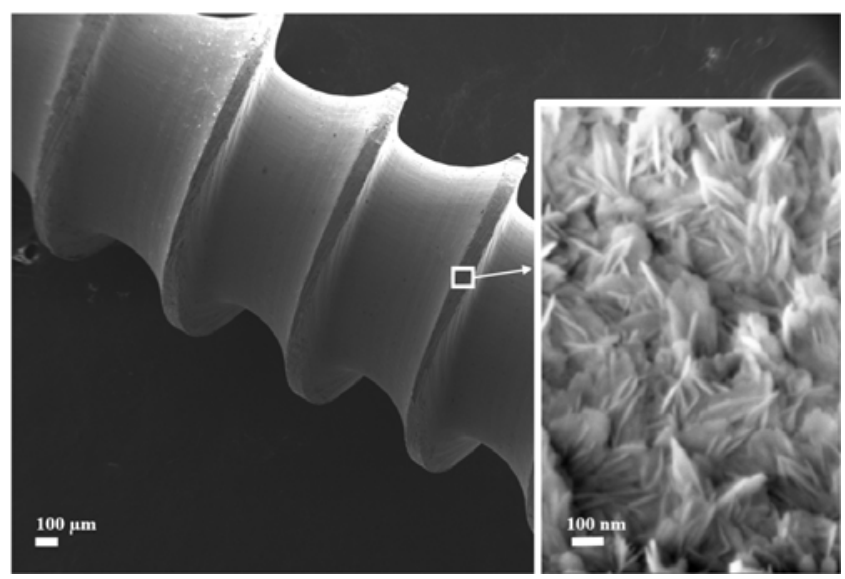

Figure 2. Magnified image of the surface of about 200nm thick $A L D$ coat on a titanium screw. The surface of the coating is formed by plate-like nanocrystalline HAp. [32,40].

Interestingly, even $20 \%$ of HAp particles (diameter $<200$ $\mathrm{nm}$ ) in PLA fiber did not reduce the mechanical strength of the fiber significantly. However, the compounded fiber increased the biocompatibility of the polymer indicating beneficial properties of HAp even as a substitute in polymer $[41,42]$. The nanostructure of HAp can enhance protein adsorption, stem cell attachment and differentiation [43].

\subsection{Nanofibrous scaffolds with electrospinnig and electroblowing}

Electrospinning is a method to produce nonwoven nanofibrous mats or felt like fabrics. Various polymeric materials are conventionally made by electrospinning but also HAp nanofibers have been produced effectively [26,27]. The fairly slow production of the electrospinning has been upgraded with a sophisticated electroblowing technique, where compressed air flow assists the spinning. [44]. The material is then heated after spinning to burn the polymeric component and annealing the crystallinity of the product. These materials cannot be used for load bearing but they can be mixed with bone marrow derived mesenchymal stem cells or peripheral blood. This kind of "void filler" treatment could be expected to be effective in bone regeneration.

It is also possible to add HAp nanoparticles up to $50 \mathrm{wt} \%$ in PLA solution and use electrospinning to make composite fibers. PLA-nanoHAp scaffolds induced differentiation of osteoblasts and osteoclasts. These cells expressed bone specific markers and the highest effect was seen with composite containing $20 \mathrm{wt} \%$ of nHAp [45].
A same kind of material was approved by FDA at 2014 as a "resorbable calcium salt bone void filler device". That material is a fibrous composite consisting of siloxane-doped calcium carbonate (vaterite) with PLA matrix, and it looks like cotton wool [46]. It may be easily filled in bone defects. The calcium-containing electrospun sol-gel-derived fibers have been shown to initiate deposition of carbonated HAp (CA) in simulated body fluid (SBF) and it had no adverse effect with MC3T-E1 cells. Similar material can be made also from pure HAp [28,29] (Fig 3.).

Since pure nano-HAp fibers can be resorbed by osteoclasts, such void filler material could be used to function as a substrate for macrophages and also bone resorbing osteoclasts, which can differentiate in situ from monocytemacrophage lineage cells of peripheral blood or tissue macrophages. Bone resorption and formation are strictly coupled during bone remodeling and resorbing osteoclasts secrete coupling factors that stimulate osteoblasts to make bone at the previously resorbed sites $[47,48]$. This kind of "autoinduction" of bone formation could be achieved also with an appropriate resorbable biomaterial [49].

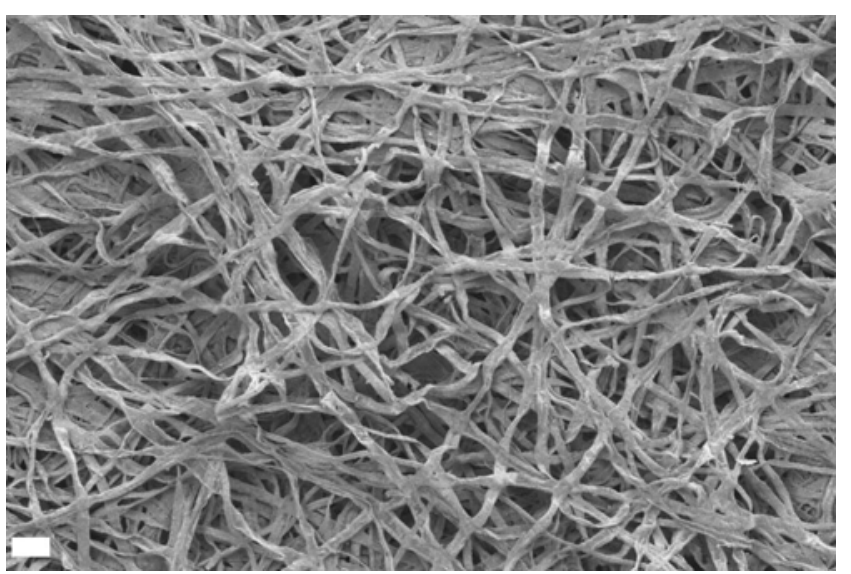

Figure 3. Electrospun HAp fibers. Scale bar $10 \mu \mathrm{m}$.

\subsection{Hydroxyapatite and bone remodeling}

HAp scaffolds and systems provide special approaches for tissue engineering. HAp can be resorbed by osteoclasts and thereby used as initiation site for osteoclastogenesis and osteoclast function [49,50]. Over $95 \%$ of new bone formation takes place on surfaces that have been resorbed and primed for bone apposition [51]. Moreover, osteoclasts are known to secrete substances, that stimulate osteoblast recruitment and bone formation [47]. Understanding the importance of remodeling and its importance in overall bone formation is important.

It was found out that indeed the biphasic calcium phosphate scaffold consisting of HAp and $\beta$-tricalcium phosphate $(\beta$ TCP) that was resorbed by osteoclasts induced bone formation. BCPs with less HA increased expression of coupling factors like sphingosine-kinase 1 and thereby osteoblastogenesis and bone formation. Thus the chemical composition of HAp affects the degree of resorption and stimulation of bone remodeling [48]. Variations from HAp stoichiometry of the calcium phosphates are important for 
their osteoclastic resorption. Also trace element content and crystallinity have big influence. Carbon content seems to be most important and CHAp is more near the resorbability of the native mineral of bone matrix [3].

The coupling phenomenon includes also mesenchymal stem cells (MSCs) and macrophages which complete the remodeling compartment [52] in bone remodeling and modeling, respectively. The most important MSC in bone regeneration seems to be bone lining cell [53]. The sealed compartment associated to circulation near bone surface or biomaterials surface will take care of the stem cell interactions and signaling between bone cells. In mature bone the lining cells are more stem than osteoblasts, indicating thet they take care of the coupling, while osteoblasts finally make new bone over the resorbed surfaces. However, with HAp inserted in osteal defects the macrophage reaction may be important in initiating the bone formation without previous resorption. So called OsteoMacs [54] make a macrophage canopy over the formation sites in modeling compartments. Without osteomacs no osteoblasts are formed at modeling sites and no new bone is formed.

The passive solubility of HAp scaffolds may play an important role. By utilization whitlockite $\left(\mathrm{Ca}_{18} \mathrm{Mg}_{2}\left(\mathrm{HPO}_{4}\right)_{2}\left(\mathrm{PO}_{4}\right)_{12}\right)$ nanoparticles, which are much more soluble than pure HAp, it was possible to stimulate bone formation and simultaneously inhibit bone resorption in a mouse model [55]. Whitlockite may transform into hydroxyapatite of new bone tissues due to dissolution of phosphate and magnesium. In this case mineral phase transformation seems to happen without cellular function. Whitlockite is dissolved and also resorbed by osteolclasts more easily than HAp. The ion release both stimulates osteoblast differentiation and inhibits osteoclastic resorption. This is another evidence of the rich variability of HAp as a biomaterial.

\section{HYDROXYAPATITE IN DRUG DELIVERY}

HAp and its binding properties for certain medicines and growth factors have been studied. For instance BMPs can have increased potency when coupled on HAp surfaces [56]. However, HAp suffer of poor drug-loading capacity and problems in releasing the substances. Pure HAp is also very slowly degrading and HAp particles may easily aggregate. However, BPs as osteoporosis drugs do have a special characteristic. They bind chemically on bone mineral and possess their function during osteoclastic bone resorption. On the other hand, BP binding capacity on HAp can be utilized also in coupling it to biomaterials and to facilitate attachment of other drugs to mineral. Various approaches for HAp drug delivery has been utilized [57].

BPs are synthetic, non-hydrolysable compounds that are structurally related to pyrophosphate. The P-C-P structure of $\mathrm{BP}$ is responsible for the ability of binding $\mathrm{Ca}^{2+}$ and thereby high affinity to HAp. BPs are poorly soluble and their bioavailability is weak. However, they absorb slowly to bone mineral and when released from bone matrix via osteoclastic resorption, they inhibit osteoclastogenesis and cause osteoclast apoptosis. The local influence on bone cells may be biphasic causing apoptosis of osteoclasts and stimulation of osteoclastogenesis. So as a drug they have profound effects on bone remodeling but they can also be utilized for coupling various molecules to mineral matrix.

\subsection{Bisphosphonate containing bone cements}

Calcium phosphate bone cements (CPCs) are applied for clinical uses because of their biocompatibility, bioactivity and easiness to adapt to the shape of bone defects. A further advantage of CPCs is the absence of heat development during hardening through dissolution and precipitation reactions. Mixing of monocalcium phosphate, monohydrate $\left[\mathrm{MCPM}, \mathrm{Ca}\left(\mathrm{H}_{2} \mathrm{PO}_{4}\right)_{2} \cdot \mathrm{H}_{2} \mathrm{O}\right], \alpha$-tricalcium phosphate $[\alpha-\mathrm{TCP}$, $\left.\mathrm{Ca}_{3}\left(\mathrm{PO}_{4}\right)_{2}\right]$, and calcium carbonate $\left(\mathrm{CC}, \mathrm{CaCO}_{3}\right)$ powders with a sodium phosphate solution leads to hardening of a paste injectable and stable at physiological temperature and $\mathrm{pH}$ [58]. The hardened CPCs was characterized as carbonated HAp with some substitution by acidic phosphate $\left(\mathrm{HPO}_{4}{ }^{2-}\right)$. Relative to cancellous bone, the compressive strength of the CPCs is greater while the tensile strength is about the same.

Some CPCs were developed to add new advantages based on the original method of transformation of $\alpha$-TCP into HAp. CPCs can be combined with BPs as functional materials implantable and injectable into bone defects. For instance, powders of $\alpha$-TCP, nanocrystalline $\mathrm{HAp}$ and $\mathrm{CaHPO}_{4}-2 \mathrm{H}_{2} \mathrm{O}$ were mixed with about $7 \mathrm{wt} \%$ of BPs such as alendronate $[59,60]$, pamidronate $[59,60]$ and zoledeonate [61]. Combination of CPCs and BPs does not affect main properties as bone cement, in terms of rate of transformation $\alpha$-TCP into calcium deficient HAp [59], injectability [59] and setting time [62]. However, it decreased mechanical properties [59]. BPs containing CPCs accelerate the proliferation and differentiation of osteoblast-like cells and inhibit osteoclasts [59-61] in vitro.

\subsection{HAp (and CA) nanocrystals as carriers for BPs}

Material properties of calcium phosphates are important for the efficiency of adsorption and desorption of BPs; for instance, crystallinity, surface area, morphology, crystalline size and $\mathrm{Ca} / \mathrm{P}$ molar ratio. The adsorption/desorption kinetics are dependent on the specific properties of the drugs [63] and morphology of HAp particles [64]. Interaction between the BP (alendronate) and HA takes place by ligand exchange in which the two phosphonate groups of the drug molecule replace two surface phosphate groups [64]. Adsorption of positively charged hydrolysis species of drug molecule is more favored on the phosphate-rich nanocrystalline HAp with needle-shaped morphology surface, while adsorption of negatively charged BPs (alendronate) is more factored on the calcium-rich nanocrystalline HAp with plate-shaped morphology. Considering that bone mineral is constituted of carbonated HAp crystals with a length of ca $100 \mathrm{~nm}$, width of ca 20-30 nm, and thickness of ca 3-6 nm, the crystalline size affects BP binding affinity.

The crystal surface and surface charges play important role in the adsorption/desorption kinetics. The interaction of BPs with (100) face of HAp crystal surface was shown using density functional theory (DFT) and molecular dynamic (MD) methods [65]. The abilities of donating electrons of the oxygen atoms of the phosphate groups are closely associated with the anti-resorptive potency. The measurements of zetapotential show that the crystal surface is modified by the 
adsorption of BPs explained by molecular charges related to the protonation of their side chain moieties [66]. Affinity constants (KL) for adsorption of BPs on HAp crystal was significantly different in the types of BPs.

Maturation of nanocrystalline HAp results in decreased affinity and adsorption of BPs. A two-step process is proposed consisting of a surface binding of BP groups to calcium ions associated with a proton release inducing the protonation of surface orthophosphate ions and their eventual solubilization [67].

The substitution of carbonate ions change the crystal structure and solubility of HAp. The solubility of carbonated HAp (CA) increased with increasing carbonate content in apatite crystal lattice because of carbonate substitution for phosphate ion sites. The rate of dissolution of CA was found to be dependent on relative undersaturation, carbonate content, and the presence of BPs [68]. Higher affinity of BPs for calcium phosphate minerals prevents dissolution by blocking active dissolution sites on the CA surface [68].

\subsection{BP immobilization on calcium phosphate coatings on titanium}

For application to prosthetic implants, BPs are adsorbed or immobilized on the implant surfaces. BPs are immobilized on thin calcium phosphate coatings on metals (Ti) by immersion in $10-2 \mathrm{M}$ of BP (pamidronate) solution for $24 \mathrm{~h}$ at $37 \mathrm{dc}$ [69]. The higher percentage of bone contact was found around the BP immobilized implants, indicating that BP immobilization on thin calcium phosphate coating on metals promoted osteogenesis [70]. BPs can be adsorbed onto the plasma sprayed HAp coated metals (cobaltchromium) commonly used for orthopedic implants [71]. XPS analyses of plasma sprayed HA coated metals after immersion in BP (pamidronate) solution for 1-24 h showed penetration of the BPs into HAp layer to depths of at least $260 \mathrm{~nm}$. Plasma sprayed HAp coated metals with adsorption of BPs decrease the activity of osteoclasts.

\subsection{BP-containing calcium phosphate microcapsules}

There is a novel carries for BPs. Calcium phosphate microcapsules were fabricated using emulsion droplets stabilized with branched copolymers as templates [72]. The calcium phosphate shells of the microcapsules were established to be calcium deficient HAp with incorporated chlorine and carbonate species. These capsule walls were made fluorescent by decoration with a fluoresceinbisphosphonate conjugate.

\section{HYDROXYAPATITE AS A SCAVENGER OF METAL IONS}

Metallosis is a severe problem and metallic implants seem to release ions and even wear debris to the surroundings of the implant. The only possible treatment to inhibit ion release is to coat the implants and passivate the surface. However, also the coating materials may release ions and molecules. The growing evidence of the adverse effects of the most widely used titanium as implant material may bring up the need for nano coatings that may catch ions that are released from metallic implants. Major causes of titanium ion release is mechanical debris during implantation and later wear and fretting [73] but interestingly, titanium is also released from implants in the absence of wear and fretting due to biochemical factors [5]. Metal ions may be released from implants by macrophages that generate superoxide anions and reactive oxygen species (ROS). Either wear debris from implants and cements or other nano or micro size components of the prosthesis may be phagocytosed by macrophages. But also without wear and fretting of titanium, the macrophages generate ROS to the surroundings. The typical wear products, high-density polyethylene particles, induced phagocytosis and generation of ROS by macrophages. This accelerates the release of titanium ions from implants into nearby tissues [4]. Titanium ion release is induced by ROS generated by macrophages activated by polymer wear debris. Metal ions are also released by organic compounds in the absence of macrophages or wear debris [4]. The ionic titanium is typically distributed and accumulated to kidneys and liver and its localization correlates with calcium [74]. Significant cytotoxicity has been demonstrated in enterocytes and osteoblasts with titanium ions and nanoparticles in vitro [75]. It has also been shown recently that titanium dioxide nanoparticles are endocytosed by osteoblasts with the aid of calcium, phosphorus and proteins that mask the particles to be internalized [76]. Since there is evidence that HAp (calcium and phosphate) may bind titanium ions and depending on the concentration of dissolved titanium the solid HAp granules will either incorporate titanium in the lattice (concentration $<200 \mathrm{ppm}$ ) or follow dissolution precipitation process (concentration $>200 \mathrm{ppm}$ ) leading to a titanium phosphate compound [77], HAp could at least partially prevent the leakage of metal ions from the implants.

There have been efforts to treat wear corrosion by developing hard ceramic coatings for the implants. It is possible to use those properly coated conventional metallic implants in patients that have metal allergy [78]. However, the ceramic coatings tend to have low fracture toughness. The cracking and delamination of the coatings may lead to fast loosing of the implant [79] and therefore thick coatings like plasma sprayed HAp are critical. Instead, novel nanocoatings with HAp should be studied further for both osteoconduction and ion scavenging functions [32].

\section{FUTURE ASPECTS}

HAp is used in hard and soft tissue therapy, bone tissue engineering and drug delivery. HAp is not a single compound but its chemical compositions and structures are highly variable. The composition of HAp can be tailored for various purposes including the substituting ions, $\mathrm{pH}$ tolerance, electrical polarization, porosity, and nanostructure, which influences greatly the surface area of the construct. There are many questions and challenges that should be studied in the future:

a. The slow degradation is a problem with HAp as bone graft, bone scaffolds and drug delivery systems. Therefore HAp based biomaterials with controlled bioresorption would be important.

b. Since the huge amount of metallic implants and the potential risk of metallosis, the ion scavenging property of 
HAp is very interesting. There is some evidence of the influence of HAp to trap titanium ions but more research should be performed.

c. New manufacturing technologies like ALD for implant coating and electrospinning for scaffolds and drug delivery systems may provide important possibilities in the future to utilize HAp.

\section{CONCLUSION}

Bone matrix is composed mainly of collagen and nonstoichiometric forms of HAp substituted with carbonate and other trace elements. Thus bone apatite is not stoichiometric HAp. Pure HAp does not function like biological minerals and it is poorly resorbed by osteoclasts. The resorbability is one goal for further developments of HAp materials for tissue engineering. HAp has also other properties like electrical polarization and nanostructure, which can be significant features for protein adsorption and behaviors of osteogenic cells. It is possible to fabricate nanocoatings on metal implants and nanofibers of HAp as cotton wool like scaffolds for cell therapy.

Hydroxyapatite biomaterials are used for drug delivery and of special interest are the BPs, that bind to mineral and accumulate in bone. They are well known antiresorptive drugs but may be used also to link other active substances to bone matrix. HAp may also bind metal ions and this metal ion scavenger function may appear to be important in preventing metallosis and metal allergy of patients receiving metal implants.

\section{CONFLICT OF INTEREST}

The authors have no conflict of interest. Miho Nakamura have received financial support (grant nr. 15KK0299) from JSPS (Japan Society for Promotion of Science).

\section{ACKNOWLEDGEMENTS}

Dr. Jani Holopainen (Univ. of Helsinki, Finland) is acknowledged for producing the ALD and electrospun materials in the illustrations and Dr. Ilkka Miinalainen from Biocenter Oulu for help with FESEM imaging.

\section{REFERENCES}

[1] Spence G, Patel N, Brooks R, Rushton N. Carbonate substituted hydroxyapatite: resorption by osteoclasts modifies the osteoblastic response. J Biomed Mater Res A 2009;90:217-224.

[2] Spence G, Patel N, Brooks R, Bonfield W, Rushton N. Osteoclastogenesis on hydroxyapatite ceramics: the effect of carbonate substitution. J Biomed Mater Res A 2010;92:1292-1300.

[3] Nakamura M, Hentunen T, Salonen J, Nagai A, Yamashita K. Characterization of bone mineral-resembling biomaterials for optimizing human osteoclast differentiation and resorption. J Biomed Mater Res A 2013;101:3141-3151.

[4] Mu Y, Kobayashi T, Sumita M, Yamamoto A, Hanawa T. Metal ion release from titanium with active oxygen species generated by rat macrophages in vitro. J Biomed Mater Res 2000;49:238-243.

[5] Mu Y, Kobayashi T, Tsuji K, Sumita M, Hanawa T. Causes of titanium release from plate and screws implanted in rabbits. J Mater Sci Mater Med 2002;13:583-588.

[6] Koutsopoulos S. Synthesis and characterization of hydroxyapatite crystals: a review study on the analytical methods. J Biomed Mater Res 2002;62:600-612.

[7] Zapanta-LeGeros R. Effect of carbonate on the lattice parameters of apatite. Nature 1965;206:403-404.

[8] Nakamura M, Hiratai R, Yamashita K. Bone mineral as an electrical energy reservoir. J Biomed Mater Res A 2012;100:1368-1374.

[9] Uskokovic V, Uskokovic DP. Nanosized hydroxyapatite and other calcium phosphates: chemistry of formation and application as drug and gene delivery agents. J Biomed Mater Res B Appl Biomater 2011;96:152-191.

[10] Zhuang Z, Aizawa M. Protein adsorption on singlecrystal hydroxyapatite particles with preferred orientation to a(b)- and c-axes. J Mater Sci Mater Med 2013;24:12111216.

[11] Zhuang Z, Fujimi TJ, Nakamura M, Konishi T, Yoshimura H, Aizawa M. Development of a,b-planeoriented hydroxyapatite ceramics as models for living bones and their cell adhesion behavior. Acta Biomater 2013;9:6732-6740.

[12] Rouahi M, Champion E, Gallet O, Jada A, Anselme K. Physico-chemical characteristics and protein adsorption potential of hydroxyapatite particles: influence on in vitro biocompatibility of ceramics after sintering. Colloids Surf B Biointerfaces 2006;47:10-19.

[13] Shen JW, Wu T, Wang Q, Pan HH. Molecular simulation of protein adsorption and desorption on hydroxyapatite surfaces. Biomaterials 2008;29:513-532.

[14] Tarafder S, Banerjee S, Bandyopadhyay A, Bose S. Electrically polarized biphasic calcium phosphates: adsorption and release of bovine serum albumin. Langmuir 2010;26:16625-16629.

[15] Itoh S, Nakamura S, Nakamura M, Shinomiya K, Yamashita K. Enhanced bone ingrowth into hydroxyapatite with interconnected pores by Electrical Polarization. Biomaterials 2006;27:5572-5579.

[16] Wang W, Itoh S, Tanaka Y, Nagai A, Yamashita K. Comparison of enhancement of bone ingrowth into hydroxyapatite ceramics with highly and poorly interconnected pores by electrical polarization. Acta Biomater 2009;5:3132-3140.

[17] Nakamura S, Kobayashi T, Nakamura M, Yamashita K. Enhanced in vivo responses of osteoblasts in electrostatically activated zones by hydroxyapatite electrets. J Mater Sci Mater Med 2009;20:99-103.

[18] Nakamura M, Soya T, Hiratai R, Nagai A, Hashimoto $\mathrm{K}$, Morita I, Yamashita K. Endothelial cell migration and morphogenesis on silk fibroin scaffolds containing 
hydroxyapatite electret. J Biomed Mater Res A 2012;100:969-977.

[19] Nakamura M, Nagai A, Hentunen T, Salonen J, Sekijima Y, Okura T, Hashimoto K, et al. Surface electric fields increase osteoblast adhesion through improved wettability on hydroxyapatite electret. ACS Appl Mater Interfaces 2009;1:2181-2189.

[20] Nakamura M, Hori N, Ando H, Namba S, Toyama T, Nishimiya N, Yamashita K. Surface free energy predominates in cell adhesion to hydroxyapatite through wettability. Mater Sci Eng C Mater Biol Appl 2016;62:283292.

[21] Bose S, Tarafder S. Calcium phosphate ceramic systems in growth factor and drug delivery for bone tissue engineering: a review. Acta Biomater 2012;8:1401-1421.

[22] Sadat-Shojai M, Khorasani MT, Dinpanah-Khoshdargi E, Jamshidi A. Synthesis methods for nanosized hydroxyapatite with diverse structures. Acta Biomater 2013;9:7591-7621.

[23] Zhou H, Lee J. Nanoscale hydroxyapatite particles for bone tissue engineering. Acta Biomater 2011;7:2769-2781.

[24] Geetha CS, Remya NS, Leji KB, Syama S, Reshma SC, Sreekanth PJ, Varma HK, et al. Cells-nano interactions and molecular toxicity after delayed hypersensitivity, in guinea pigs on exposure to hydroxyapatite nanoparticles. Colloids Surf B Biointerfaces 2013;112:204-212.

[25] Motskin M, Wright DM, Muller K, Kyle N, Gard TG, Porter AE, Skepper JN. Hydroxyapatite nano and microparticles: correlation of particle properties with cytotoxicity and biostability. Biomaterials 2009;30:33073317.

[26] Holopainen J, Penttinen T, Santala E, Ritala M. Needleless electrospinning with twisted wire spinneret. Nanotechnology 2015;26:025301-4484/26/2/025301. Epub 2014 Dec 16.

[27] Holopainen J, Santala E, Heikkila M, Ritala M. Electrospinning of calcium carbonate fibers and their conversion to nanocrystalline hydroxyapatite. Mater Sci Eng C Mater Biol Appl 2014;45:469-476.

[28] Deliormanli AM. Preparation, in vitro mineralization and osteoblast cell response of electrospun 13-93 bioactive glass nanofibers. Mater Sci Eng C Mater Biol Appl 2015;53:262-271

[29] Pasuri J, Holopainen J, Kokkonen H, Persson M, Kauppinen K, Lehenkari P, Santala E, et al. Osteoclasts in the interface with electrospun hydroxyapatite. Colloids Surf B Biointerfaces 2015;135:774-783.

[30] Surmenev RA, Surmeneva MA, Ivanova AA. Significance of calcium phosphate coatings for the enhancement of new bone osteogenesis--a review. Acta Biomater 2014;10:557-579.

[31] Putkonen M, Sajavaara T, Niinisto L, Keinonen J. Analysis of ALD-processed thin films by ion-beam techniques. Anal Bioanal Chem 2005;382:1791-1799.
[32] Holopainen J, Kauppinen K, Mizohata K, Santala E, Mikkola E, Heikkila M, Kokkonen H, et al. Preparation and bioactive properties of nanocrystalline hydroxyapatite thin films obtained by conversion of atomic layer deposited calcium carbonate. Biointerphases 2014;9:031008.

[33] Vallet-Regí M, González-Calbet JM. Calcium phosphates as substitution of bone tissues. 2004;32:1-31.

[34] Sun W, Chu C, Wang J, Zhao H. Comparison of periodontal ligament cells responses to dense and nanophase hydroxyapatite. J Mater Sci Mater Med 2007;18:677-683.

[35] Lin K, Yuan W, Wang L, Lu J, Chen L, Wang Z, Chang $\mathrm{J}$. Evaluation of host inflammatory responses of betatricalcium phosphate bioceramics caused by calcium pyrophosphate impurity using a subcutaneous model. J Biomed Mater Res B Appl Biomater 2011;99:350-358.

[36] Kim HM, Kim YS, Woo KM, Park SJ, Rey C, Kim Y, Kim JK, et al. Dissolution of poorly crystalline apatite crystals by osteoclasts determined on artificial thin-film apatite. J Biomed Mater Res 2001;56:250-256.

[37] de Bruijn JD, Bovell YP, Davies JE, van Blitterswijk CA. Osteoclastic resorption of calcium phosphates is potentiated in postosteogenic culture conditions. J Biomed Mater Res 1994;28:105-112.

[38] Botelho CM, Brooks RA, Spence G, McFarlane I, Lopes MA, Best SM, Santos JD, et al. Differentiation of mononuclear precursors into osteoclasts on the surface of Sisubstituted hydroxyapatite. J Biomed Mater Res A 2006;78:709-720.

[39] Broggini N, Bosshardt DD, Jensen SS, Bornstein MM, Wang CC, Buser D. Bone healing around nanocrystalline hydroxyapatite, deproteinized bovine bone mineral, biphasic calcium phosphate, and autogenous bone in mandibular bone defects. J Biomed Mater Res B Appl Biomater 2015;103:1478-1487.

[40] Holopainen J. Bioactive Coatings and Fibers for Bone Implants and Scaffolds by Atomic Layer Deposition, Electrospinning, Solution Blow Spinning and Electroblowing. 2017-01-13;

[41] Persson M, Lorite GS, Cho SW, Tuukkanen J, Skrifvars M. Melt spinning of poly(lactic acid) and hydroxyapatite composite fibers: influence of the filler content on the fiber properties. ACS Appl Mater Interfaces 2013;5:6864-6872.

[42] Persson M, Lorite GS, Kokkonen HE, Cho SW, Lehenkari PP, Skrifvars M, Tuukkanen J. Effect of bioactive extruded PLA/HA composite films on focal adhesion formation of preosteoblastic cells. Colloids Surf B Biointerfaces 2014;121:409-416.

[43] Xia L, Lin K, Jiang X, Xu Y, Zhang M, Chang J, Zhang $Z$. Enhanced osteogenesis through nano-structured surface design of macroporous hydroxyapatite

bioceramic scaffolds via activation of ERK and p38 MAPK signaling pathways. J Mater Chem B 2013;1:5403.

[44] Holopainen J, Ritala M. Rapid production of bioactive hydroxyapatite fibers via electroblowing. 2016;36:32193224. 
[45] Morelli S, Salerno S, Holopainen J, Ritala M, De Bartolo L. Osteogenic and osteoclastogenic differentiation of co-cultured cells in polylactic acid-nanohydroxyapatite fiber scaffolds. J Biotechnol 2015;204:53-62.

[46] Poologasundarampillai G, Wang D, Li S, Nakamura J, Bradley R, Lee PD, Stevens MM, et al. Cotton-wool-like bioactive glasses for bone regeneration. Acta Biomater 2014;10:3733-3746.

[47] Lotinun S, Kiviranta R, Matsubara T, Alzate JA, Neff L, Luth A, Koskivirta I, et al. Osteoclast-specific cathepsin $\mathrm{K}$ deletion stimulates S1P-dependent bone formation. J Clin Invest 2013;123:666-681.

[48] Shiwaku Y, Neff L, Nagano K, Takeyama K, de Bruijn J, Dard M, Gori F, et al. The Crosstalk between Osteoclasts and Osteoblasts Is Dependent upon the Composition and Structure of Biphasic Calcium Phosphates. PLoS One 2015; 10:e0132903.

[49] Kylmaoja E, Nakamura M, Tuukkanen J. Osteoclasts and Remodeling Based Bone Formation. Curr Stem Cell Res Ther 2016;11:626-633.

[50] Kylmaoja E, Kokkonen H, Kauppinen K, Hussar P, Sato T, Haugan K, Larsen BD, et al. Osteoclastogenesis is influenced by modulation of gap junctional communication with antiarrhythmic peptides. Calcif Tissue Int 2013;92:270281 .

[51] Hattner R, Epker BN, Frost HM. Suggested sequential mode of control of changes in cell behaviour in adult bone remodelling. Nature 1965;206:489-490.

[52] Hauge EM, Qvesel D, Eriksen EF, Mosekilde L, Melsen F. Cancellous bone remodeling occurs in specialized compartments lined by cells expressing osteoblastic markers. J Bone Miner Res 2001;16:1575-1582.

[53] Matic I, Matthews BG, Wang X, Dyment NA, Worthley DL, Rowe DW, Greevic D, et al. Quiescent Bone Lining Cells Are a Major Source of Osteoblasts During Adulthood. Stem Cells 2016;34:2930-2942.

[54] Chang MK, Raggatt LJ, Alexander KA, Kuliwaba JS, Fazzalari NL, Schroder K, Maylin ER, et al. Osteal tissue macrophages are intercalated throughout human and mouse bone lining tissues and regulate osteoblast function in vitro and in vivo. J Immunol 2008;181:1232-1244.

[55] Kim HD, Jang HL, Ahn HY, Lee HK, Park J, Lee ES, Lee EA, et al. Biomimetic whitlockite inorganic nanoparticles-mediated in situ remodeling and rapid bone regeneration. Biomaterials 2017;112:31-43.

[56] Schuessele A, Mayr H, Tessmar J, Goepferich A. Enhanced bone morphogenetic protein-2 performance on hydroxyapatite ceramic surfaces. J Biomed Mater Res A 2009;90:959-971.

[57] Bose S, Tarafder S. Calcium phosphate ceramic systems in growth factor and drug delivery for bone tissue engineering: a review. Acta Biomater 2012;8:1401-1421.

[58] Constantz BR, Ison IC, Fulmer MT, Poser RD, Smith ST, VanWagoner M, Ross J, et al. Skeletal repair by in situ formation of the mineral phase of bone. Science 1995;267:1796-1799.

[59] Panzavolta S, Torricelli P, Bracci B, Fini M, Bigi A. Alendronate and Pamidronate calcium phosphate bone cements: setting properties and in vitro response of osteoblast and osteoclast cells. J Inorg Biochem 2009; 103:101-106.

[60] Boanini E, Torricelli P, Gazzano M, Giardino R, Bigi A. Alendronate-hydroxyapatite nanocomposites and their interaction with osteoclasts and osteoblast-like cells. Biomaterials 2008;29:790-796.

[61] Boanini E, Torricelli P, Gazzano M, Fini M, Bigi A. The effect of zoledronate-hydroxyapatite nanocomposites on osteoclasts and osteoblast-like cells in vitro. Biomaterials 2012;33:722-730.

[62] Schnitzler V, Fayon F, Despas C, Khairoun I, Mellier C, Rouillon $\mathrm{T}$, Massiot $\mathrm{D}$, et al. Investigation of alendronatedoped apatitic cements as a potential technology for the prevention of osteoporotic hip fractures: critical influence of the drug introduction mode on the in vitro cement properties. Acta Biomater 2011;7:759-770.

[63] Puljula E, Turhanen P, Vepsalainen J, Monteil M, Lecouvey M, Weisell J. Structural requirements for bisphosphonate binding on hydroxyapatite: NMR study of bisphosphonate partial esters. ACS Med Chem Lett 2015;6:397-401.

[64] Palazzo B, Iafisco M, Laforgia M, Margiotta N, Natile G, Bianchi C, Walsh D, et al. Biomimetic HydroxyapatiteDrug Nanocrystals as Potential Bone Substitutes with Antitumor Drug Delivery Properties. 2007;17:2180-2188.

[65] Chen C, Xia M, Wu L, Zhou C, Wang F. Modeling the interaction of seven bisphosphonates with the hydroxyapatite(100) face. J Mol Model 2012;18:4007-4012.

[66] Nancollas GH, Tang R, Phipps RJ, Henneman Z, Gulde $\mathrm{S}, \mathrm{Wu} \mathrm{W}$, Mangood A, et al. Novel insights into actions of bisphosphonates on bone: differences in interactions with hydroxyapatite. Bone 2006;38:617-627.

[67] Pascaud P, Gras P, Coppel Y, Rey C, Sarda S. Interaction between a bisphosphonate, tiludronate, and biomimetic nanocrystalline apatites. Langmuir 2013;29:2224-2232.

[68] Henneman ZJ, Nancollas GH, Ebetino FH, Russell RG, Phipps RJ. Bisphosphonate binding affinity as assessed by inhibition of carbonated apatite dissolution in vitro. J Biomed Mater Res A 2008;85:993-1000.

[69] Yoshinari M, Oda Y, Ueki H, Yokose S. Immobilization of bisphosphonates on surface modified titanium. Biomaterials 2001;22:709-715.

[70] Yoshinari M, Oda Y, Inoue T, Matsuzaka K, Shimono $\mathrm{M}$. Bone response to calcium phosphate-coated and bisphosphonate-immobilized titanium implants. Biomaterials 2002;23:2879-2885.

[71] McLeod K, Kumar S, Smart RSC, Dutta N, Voelcker $\mathrm{NH}$, Anderson GI, Sekel R. XPS and bioactivity study of the 
bisphosphonate pamidronate adsorbed onto plasma sprayed hydroxyapatite coatings. Appl Surf Sci 2006;253:2644-2651.

[72] Bell RV, Rochford LA, de Rosales RTM, Stevens M, Weaver JVM, Bon SAF. Fabrication of calcium phosphate microcapsules using emulsion droplets stabilized with branched copolymers as templates. J Mater Chem B :5544.

[73] Laurencon J, Augsburger M, Faouzi M, Becce F, Hassani H, Rudiger HA. Systemic Metal Ion Levels in Patients With Modular-Neck Stems: A Prospective Cohort Study. J Arthroplasty 2016;31:1750-1755.

[74] Golasik M, Wrobel P, Olbert M, Nowak B, Czyzycki M, Librowski T, Lankosz M, et al. Does titanium in ionic form display a tissue-specific distribution? Biometals 2016;29:487-494.

[75] Soto-Alvaredo J, Blanco E, Bettmer J, Hevia D, Sainz RM, Lopez Chaves C, Sanchez C, et al. Evaluation of the biological effect of Ti generated debris from metal implants: ions and nanoparticles. Metallomics 2014;6:1702-1708.

[76] Ribeiro AR, Gemini-Piperni S, Travassos R, Lemgruber L, Silva RC, Rossi AL, Farina M, et al. Trojan-Like Internalization of Anatase Titanium Dioxide Nanoparticles by Human Osteoblast Cells. Sci Rep 2016;6:23615.

[77] Ribeiro CC, Gibson I, Barbosa MA. The uptake of titanium ions by hydroxyapatite particles-structural changes and possible mechanisms. Biomaterials 2006;27:1749-1761.

[78] Thomas P, Weik T, Roider G, Summer B, Thomsen M. Influence of Surface Coating on Metal Ion Release: Evaluation in Patients With Metal Allergy. Orthopedics 2016;39:S24-30.

[79] Rahaman MN, Yao A, Bal BS, Garino JP, Ries MD. Ceramics for Prosthetic Hip and Knee Joint Replacement. J Am Ceram Soc 2007;90:1965-1988. 